\title{
Malignant Vulvar Sweat Gland Neoplasm
}

National Cancer Institute

\section{Source}

National Cancer Institute. Malignant Vulvar Sweat Gland Neoplasm. NCI Thesaurus. Code C40304.

A malignant neoplasm that arises from sweat glands in the vulva. Representative examples include eccrine adenocarcinoma, apocrine adenocarcinoma, and Paget disease. 